\title{
Uni and Bi-directional Exchange Flows in a Large Scale Rotating Channel
}

\author{
Claudia ADDUCE ${ }^{1, \bigotimes}$, Maria Chiara DE FALCO ${ }^{1}$, Alan CUTHBERTSON $^{2}$, \\ Maria Eletta NEGRETTI ${ }^{3}$, Janek LAANEARU ${ }^{4}$, Daniela MALCANGIO ${ }^{5}$, \\ and Joel SOMMERIA ${ }^{3}$ \\ ${ }^{1}$ University Roma Tre, Rome, Italy \\ ${ }^{2}$ University of Dundee, Dundee, UK \\ ${ }^{3}$ LEGI, UGA/CNRS, Grenoble, France \\ ${ }^{4}$ Tallinn University of Technology, Tallinn, Estonia \\ ${ }^{5}$ Polytechnic University of Bari, Bari, Italy \\ claudia.adduce@uniroma3.it
}

\begin{abstract}
Laboratory experiments were performed at the Coriolis Rotating Platform to study uni and bi-directional exchange flows in a trapezoidal channel. PIV and conductivity probes were used to measure velocity fields and density profiles. The rotation rate and the freshwater flowrate were varied. The stratified flow dynamics was found to depend on the Burger number, $\mathrm{Bu}$, and for $\mathrm{Bu}<0.5$ unsteady exchange flows develop. Both the ambient rotation and freshwater flowrate affect the transverse velocity distribution and leads to the partial blockage of the lower saline outflow for the largest freshwater inflows. In addition, shear-driven interfacial instabilities are analysed and for larger rotation rates the mixing layer thickness increases.
\end{abstract}

Keywords: stratified exchange flows, rotating flows, interfacial instabilities.

\section{INTRODUCTION}

Uni- and bi-directional exchange flows occur within estuaries and sea straits when horizontal density differences or pressure gradients are present between the adjacent water bodies. The 
nature of these flows depends on both Coriolis effects due to the Earth's rotation and the topographic controls imposed by seafloor bathymetry and channel shape. These factors have a significant influence on both internal mixing and secondary circulations generated by exchange flows (De Falco et al. 2021). Understanding of these uni- and bi-directional flow processes is relevant in coastal regions, where water and nutrient exchanges between estuaries and open marine waters are regulated by channel topography (Cuthbertson et al. 2006) with significant implications for the intrusion of saline marine waters (Matthäus and Lass 1995).

\section{EXPERIMENTAL DETAILS}

Laboratory experiments were conducted in the Coriolis Rotating Platform at LEGI, which consists of a $13 \mathrm{~m}$ diameter and $1.2 \mathrm{~m}$ deep circular tank that can be rotated at a constant angular velocity. A trapezoidal cross-section channel of length $6.5 \mathrm{~m}$ was positioned in the tank. The trapezoidal section had a $2 \mathrm{~m}$ top width, $1 \mathrm{~m}$ bottom width and $0.5 \mathrm{~m}$ total depth, with side slopes of $\alpha_{\mathrm{s}}=45^{\circ}$. A saline water flowrate $Q_{1}$ and a fresh water flowrate $Q_{2}$, with $q^{*}=Q_{2 /} Q_{1}$, were fed into the channel with opposite directions and a uni- or two-layer exchange flow was developed. The rotation rate, $\Omega$, of the tank and the freshwater flowrate $Q_{2}$ were varied. Velocity fields, in eleven sections spanning the trapezoidal cross section, and density profiles were measured by PIV and conductivity probes, respectively. Figure 1 shows the effect of the varied parameters on the interface between the salty and freshwater flow.
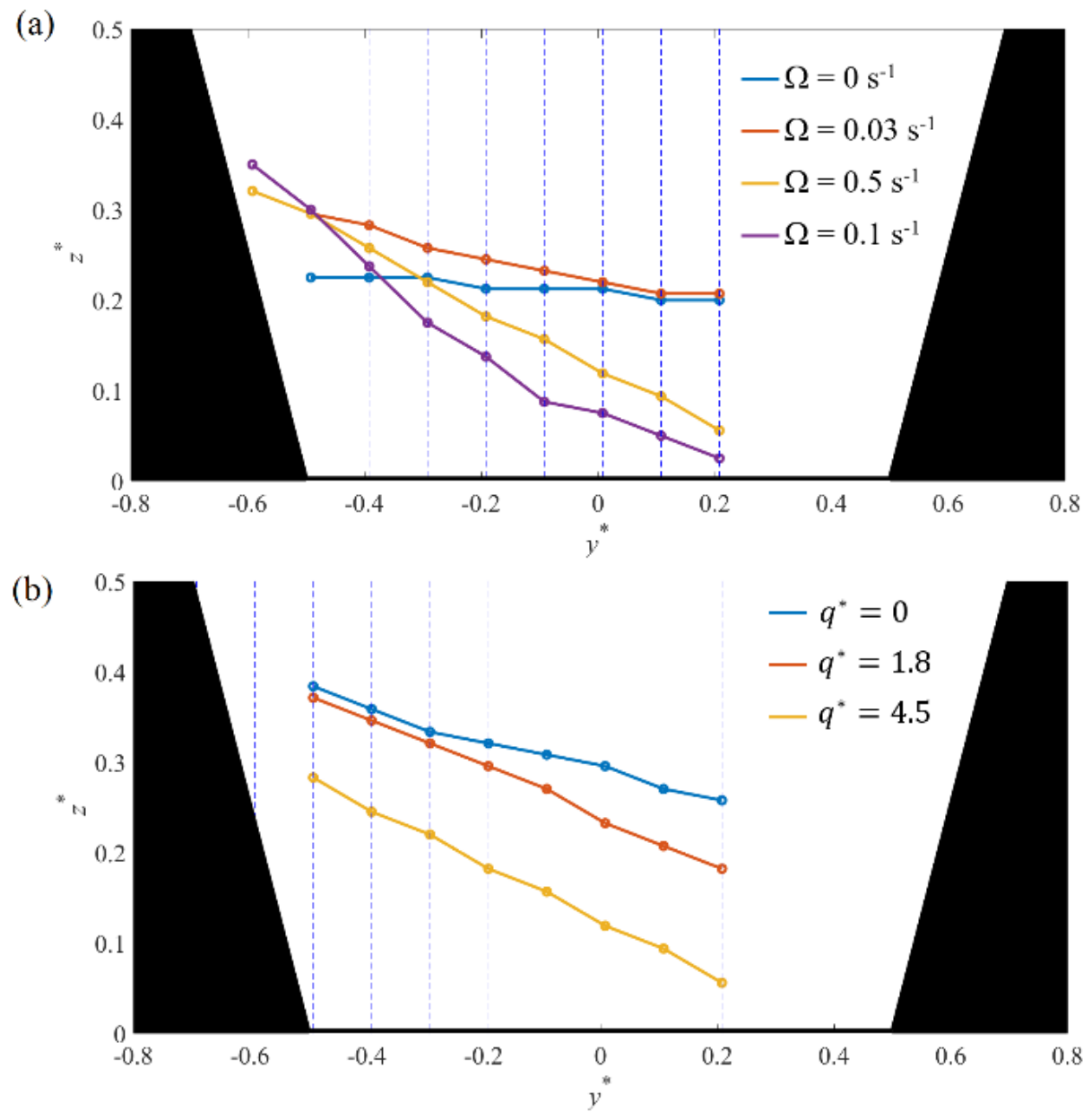

Fig. 1. Cross channel variation of zero-velocity elevation in all the measured PIV sections: (a) rotating experiments with $q^{*}=4.5$, (b) rotating experiments with $\Omega=0.05 \mathrm{~s}^{-1}$. 
References

Cuthbertson, A.J.S., J. Laanearu, and P.A. Davies (2006), Buoyancy-driven two-layer exchange flows across a slowly submerging barrier, Environ. Fluid Mech. 6, 133-151, DOI: 10.1007/s10652005-5460-6.

De Falco, M.C., C. Adduce, A. Cuthbertson, M.E. Negretti, J. Laanearu, D. Malcangio, and J. Sommeria (2021), Experimental study of uni-and bi-directional exchange flows in a large-scale rotating trapezoidal channel, Phys. Fluids 33, 3, 036602, DOI: 10.1063/5.0039251.

Matthäus, W., and H.U. Lass (1995), The recent salt inflow into the Baltic Sea, J. Phys. Oceanogr. 25, 2, 280-286, DOI: 10.1175/1520-0485(1995)025<0280:TRSIIT>2.0.CO;2.

Received 22 March 2021

Accepted 12 April 2021 